\title{
Risk factors for strabismus in children born before 32 weeks' gestation
}

\author{
Philippa M Pennefather, Michael P Clarke, Nicholas P Strong, David G Cottrell, \\ Jonathan Dutton, Win Tin
}

\begin{abstract}
Aim-To investigate risk factors associated with strabismus in children born prematurely.

Methods-Prospective study of all children born before 32 weeks' gestation between 1 January 1990 and 31 December 1991 in a geographically defined population of approximately 3 million in the Northern Region of the United Kingdom. All children were examined aged 2 years by the same ophthalmologist and paediatrician.

Results-558 children $(98.6 \%$ of study group) were examined. Logistic regression showed an increased risk of strabismus in children with cicatricial retinopathy of prematurity $(p=0.02)$, refractive error $(p=0.003)$, family history of strabismus $(p<0.0001)$, and poor neurodevelopmental outcome $(p<0.0001)$, in particular impaired locomotor skills $(p=0.008)$ and hand-eye coordination $(p=0.001)$. Gestational age and regressed acute ROP were not independent risk factors for strabismus $(p=0.92$ and 0.85 respectively).
\end{abstract}

Conclusions-This study has identified factors which are independently related to strabismus (although not necessarily causative) and others which are related only indirectly. This may contribute both to the management of children born prematurely and to future studies of the aetiology of strabismus.

(Br F Ophthalmol 1999;83:514-518)

Department of Clinical Audit, Southport and

Formby District

General Hospital, Southport

J Dutton

Regional Maternity

Survey Office,

Newcastle upon Tyne

W Tin

Correspondence to: Mrs P M Pennefather, St Paul's Eye Unit, Royal Liverpool University

Hospital, Prescot Street,

Liverpool L7 8XP.

Accepted for publication 22 October 1998 ocular abnormalities. ${ }^{10}$ To avoid this bias we have studied the outcome of premature birth in a geographically defined population, served by five referral hospitals and 15 peripheral hospitals. This paper documents the prevalence of strabismus in this cohort when tested between 2 and 3 years of age and investigates the relation between strabismus and gestational age at birth, ROP, and neurological outcome.

\section{Methods}

The study group consisted of all children born at less than 32 weeks' gestation between 1 January 1990 and 31 December 1991 to mothers resident in the Northern Region of the National Health Service (even if born outside the region) who survived until 2 years old. This region has a population of approximately 3 million. The cohort has been described elsewhere ${ }^{11}$ with the addition of five children who were initially overlooked but identified after the neonatal period on checking the maternal dates and 18 week fetal ultrasound scans of all those children initially thought to be 32 or 33 weeks' gestation at birth. Informed parental consent and ethics committee approval were obtained.

EXAMINATION OF CHILDREN AT 2 YEARS

All children were reviewed by one ophthalmologist when aged between 2 and 3 years old. The examiner was masked to gestation age, neonatal events, and the results of retrospective review of the case notes.

Examination comprised visual acuity (usually by Kay pictures), cover tests for near and distant targets, extraocular movements, and fields to confrontation. Topical cyclopentolate $1 \%$ was instilled 20 minutes before refraction and funduscopy. Refraction results were corrected for working distance but no additional adjustment was made for the effect of topical cycloplegics. A child was considered to have a significant refractive error if there was hypermetropia $>4$ dioptres (D) or astigmatism $>1.25 \mathrm{D}$ in either eye or anisometropia $>1 \mathrm{D}$. Cicatricial ROP was defined as tractional changes of the posterior pole vessels or at the periphery or worse. A family history of strabismus was defined as two or more first or second degree relatives with strabismus or one first or second degree relative and two or more third degree relatives with strabismus. 
Table 1 Strabismus in 2 year old children born prematurely, according to gestational age at birth

\begin{tabular}{|c|c|c|c|c|c|c|}
\hline \multirow[b]{2}{*}{$\begin{array}{l}\text { Gestational } \\
\text { age }\end{array}$} & \multirow[b]{2}{*}{ Total no } & \multirow[b]{2}{*}{$\begin{array}{l}\text { No of squint } \\
\text { (\% total) }\end{array}$} & \multicolumn{3}{|c|}{ Squint associated with } & \multirow[b]{2}{*}{$\begin{array}{l}\text { No other } \\
\text { abnormality }\end{array}$} \\
\hline & & & Cic ROP & $C P t$ & $\begin{array}{l}\text { Refractive } \\
\text { error } \neq\end{array}$ & \\
\hline 23 & 4 & $2(50)$ & 2 & 0 & 0 & 0 \\
\hline 24 & 8 & $2(25)$ & 1 & 0 & 1 & 0 \\
\hline 25 & 19 & $4(21)$ & 3 & 1 & 0 & 0 \\
\hline 26 & 26 & $6(23)$ & 1 & 1 & 3 & 1 \\
\hline 27 & 52 & $11(21)$ & 2 & 5 & 2 & 2 \\
\hline 28 & 67 & $9(13)$ & 1 & 3 & 0 & 5 \\
\hline 29 & 96 & $8(8)$ & 0 & 5 & 1 & 2 \\
\hline 30 & 140 & $18(13)$ & 1 & 5 & 3 & 9 \\
\hline 31 & 146 & $10(7)$ & 0 & 3 & 1 & 6 \\
\hline Total & 558 & $70(12.5)$ & 11 & 23 & 11 & 25 \\
\hline
\end{tabular}

${ }^{\star}$ Gestational age in completed weeks.

†Also 5 ROP patients had cerebral palsy $(\mathrm{CP})$ and $4 \mathrm{CP}$ patients were hypermetropic.

$\ddagger$ Refractive errors of anisometropia $>1 \mathrm{D}$, astigmatism $>1.25 \mathrm{D}$ and hypermetropia $>4 \mathrm{D}$.

On a separate occasion, all children were reviewed by one paediatrician. Examination included medical, neurological, and developmental assessment, using the Griffiths Mental Development Scales (GMDS). ${ }^{112}$ The GMDS consist of five groups of tests (locomotor, personal-social, hearing and speech, handeye coordination, and performance) which contribute equally to the total GMDS score (general developmental quotient).

RETROSPECTIVE REVIEW OF PATIENT RECORDS Once the child had been examined all available notes were scrutinised for any additional information such as the outcome of ocular examination under anaesthesia. This information was used to augment that obtained from clinical examination.

Neonatal records were reviewed for the results of screening for acute ROP and treatment by cryotherapy. Screening for acute ROP had been performed in individual neonatal units by local ophthalmologists. In general, neonates were examined first at 32 weeks' post menstrual age, after pupil dilatation with phenylephrine $2.5 \%$ and cyclopentolate $0.5 \%$ using indirect ophthalmoscopy with a speculum and indentor to rotate the eye. Findings were documented in accordance with the international classification of $\mathrm{ROP}^{13}$ - namely, stage 1, demarcation line; stage 2, ridge; stage 3, extraretinal fibrovascular proliferation; stage 4, partial retinal detachment; and stage 5, retinal detachment. Threshold disease was defined as in the Multicenter Trial of Cryotherapy for Retinopathy of Prematurity study ${ }^{14}$ - namely, at least 5 contiguous clock hours or 8 cumulative hours of stage 3 ROP in zone one or two in the presence of "plus" disease (dilatation and tortuosity of the posterior retinal vessels).

Cranial ultrasound scans were performed in some neonatal units as a routine at 1 and 6 weeks as well as if there was a clinical indication while in other units neonates were scanned only if there was a clinical indication. Cranial ultrasound results were grouped into those showing major abnormalities (cerebral parenchymal involvement, significant ventriculomegaly or intraventricular haemorrhage with ventricular dilatation), those with minor abnormalities and those showing no abnormality, as described by the Northern Neonatal Nurs- ing Initiative Trial Group for this cohort of children. $^{15}$

Statistical analysis was by $\chi^{2}$ tests with a continuity correction and univariate and multiple logistic regression.

\section{Results}

Of the 566 eligible children, 558 two year olds (98.6\% of the study group) were examined by both the paediatrician and ophthalmologist. Strabismus was present in $70(12.5 \%)$. Before any surgery, $59(10.6 \%)$ had an esotropia and $11(2 \%)$ had an exotropia. Screening for acute ROP was documented in 253 children, of whom 200 had no ROP, 22 had stage 1, 14 had stage 2, and 17 had stage 3, of whom 14 reached threshold. Cicatricial ROP developed in 27 eyes of $16(2.9 \%)$ children, ranging from straightening of arcade vessels to open funnel detachments. Disabling cerebral palsy (CP, severe enough to interfere with normal activities for the child's age such as unable to walk) was present in 41 ( $7.3 \%$ of study group) and non-disabling CP in $13(2.3 \%)$. Cranial ultrasound scans were performed in 396 neonates of whom 230 were normal, 123 had a minor abnormality, and 43 had a severe abnormality.

The distribution of strabismus according to gestational age (Table 1) shows an increased incidence of strabismus with decreasing gestational age $(p=0.0004)$. Strabismus was associated with increased severity of acute ROP $(p=0.0001)$, with cicatricial ROP $(11 / 16$ children $(68.8 \%)$, Table $1, \mathrm{p}<0.0001)$ and with $\mathrm{CP}$, strabismus being present in $28(51.9 \%)$ of CP patients (Table 1, p<0.0001). A decreased general developmental quotient (GMDS score) was associated with an increased incidence of strabismus $(p<0.0001)$. As these variables are interrelated, logistic regression was used to identify which factors were merely dependent variables and which contributed independently in predicting strabismus. Logistic regression demonstrated that gestational age was no longer statistically significant $(p=0.92)$ once logistical regression was performed using the following factors: cicatricial ROP $(p=0.05)$, refractive error $(p=0.006)$, family history of strabismus $(p<0.0001)$, and general developmental quotient $(p<0.0001)$. Cranial ultrasound abnormality was not a significant predictor of strabismus, whether classified as severe, minor, or absent $(p=0.37)$ or severe or absent $(p=0.37)$. The stage of acute ROP was statistically significant $(p=0.05)$ but cicatricial ROP was a better predictor of strabismus. Thus, once cicatricial ROP was included in the logistic regression $(p=0.05)$, the stage of acute ROP ceased to be statistically significant $(p=0.85)$. Similarly, CP was statistically significant in logistic regression $(p<0.0001)$ in the absence of the general developmental quotient but once the general developmental quotient was included, CP was no longer statistically significant $(\mathrm{p}=0.26)$.

Because the general developmental quotient is being restandardised, the results from the 502 preterm children in this study without severe disability were used to define the lower 


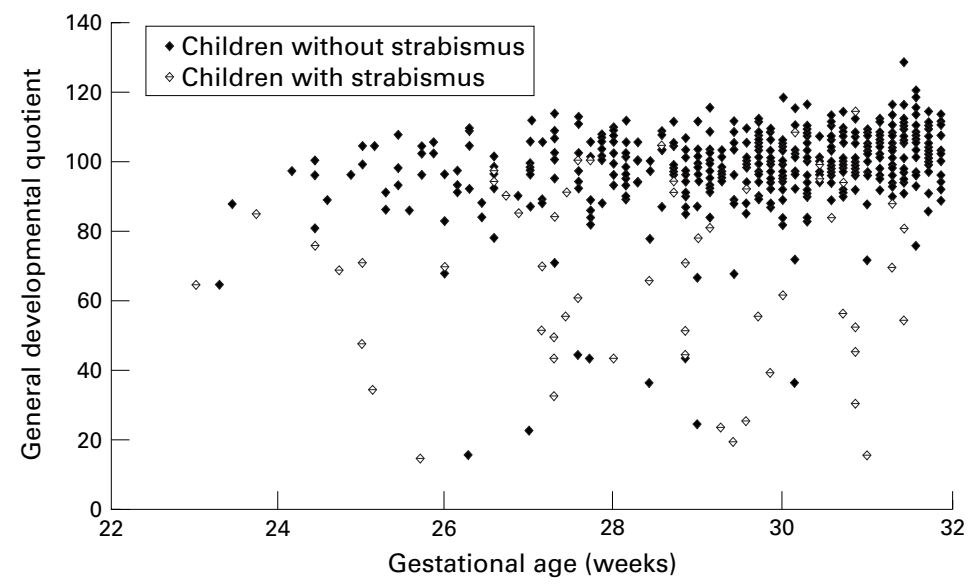

Figure 1 Distribution of children with strabismus according to gestational age at birth and general developmental quotient.

limit of the "normal" range. ${ }^{11}$ These scores had an essentially normal distribution (mean 100.2, SD 7.4). We defined generalised delay as a developmental quotient of $<78$ (3 SD below the mean).

The distribution of strabismus according to general developmental quotient and gestational age at birth is shown in Figure 1. The association between general developmental quotient and strabismus was not solely due to the high incidence of strabismus in those with developmental delay. Multiple regression shows that by comparison with those with a general developmental quotient of over 100, there was a significantly higher risk of strabismus not only in those with generalised developmental delay (general developmental quotient less than 78) but also in those with a general developmental quotient of $78-100$ (Table 2) The results were similar using different limits for the groups of general developmental quotient. Thus, for a general developmental quotient of $86-100$ (2 SD below the mean) the relative risk was 2.67 (95\% CI $1.14-6.29, \mathrm{p}=0.02)$. Using the conventional general developmental quotient mean of 100 and SD of $10,{ }^{12}$ those with scores of $80-100$

Table 2 Factors associated with strabismus in children born before 32 weeks'gestation

\begin{tabular}{llll}
\hline Factors associated with strabismus & Odds ratio & $\begin{array}{l}95 \% \text { Confidence } \\
\text { interval }\end{array}$ & p Value \\
\hline Cicatricial ROP & 4.94 & $1.10-22.12$ & 0.037 \\
$\begin{array}{l}\text { Family history } \\
\text { Refractive error }\end{array}$ & 4.15 & $2.19-7.88$ & $<0.00005$ \\
$\begin{array}{l}\text { Below average general developmental } \\
\quad \text { quotient (78-100) }\end{array}$ & 2.71 & $1.30-5.66$ & 0.008 \\
$\begin{array}{l}\text { Developmental delay (<77) } \\
\text { Oring }\end{array}$ & 3.34 & $1.46-7.64$ & 0.004 \\
\hline
\end{tabular}

Other factors included in the logistic regression which were not statistically significant were gestational age, stage of acute ROP, cerebral palsy, and neonatal cranial ultrasound abnormalities.

Table 3 Factors associated with strabismus in children born before 32 weeks' gestation

\begin{tabular}{llll}
\hline Factors associated with strabismus & Odds ratio & $\begin{array}{l}\text { 95\% Confidence } \\
\text { interval }\end{array}$ & p Value \\
\hline Cicatricial ROP & 5.89 & $1.27-27.33$ & 0.024 \\
Family history & 4.31 & $2.25-8.26$ & $<0.00005$ \\
Refractive error & 3.08 & $1.46-6.52$ & 0.003 \\
Delayed locomotor skills & 4.17 & $1.45-11.99$ & 0.008 \\
Delayed hand-eye coordination & 7.74 & $2.26-26.51$ & 0.001 \\
\hline
\end{tabular}

Other factors included in the logistic regression which were not statistically significant were gestational age, stage of acute ROP and the remaining subgroups for the Griffiths neurodevelopmental score (personal-social, hearing and speech, and performance). had a relative risk of strabismus of $3.31(95 \%$ CI $1.44-7.56, \mathrm{p}=0.005)$.

The general developmental quotient (GMDS score) is derived equally from the mean of five subgroups: locomotor, personalsocial, hearing and speech, hand-eye coordination, and performance. The subgroups of the general developmental quotient which accounted for the statistically significant relation between strabismus and general developmental quotient were further investigated by logistic regression: there was a statistically significantly relation between strabismus and hand-eye coordination $(p=0.0006)$ and locomotor skills $(\mathrm{p}=0.006)$ but not with hearing and speech $(\mathrm{p}=0.19)$, personal-social $(\mathrm{p}=0.40)$ or performance $(p=0.30)$. Table 3 shows the relative risk of strabismus for the five factors associated with strabismus - namely, cicatricial ROP, refractive error, family history, hand-eye coordination, and locomotor skills. The hand-eye and locomotor scores did not show any significant difference in predicting strabismus, between those scoring greater than the mean and those whose score lay between the mean and 3 SD below the mean, unlike the general developmental quotient (Table 2).

\section{Discussion}

Previous studies of premature infants have noted a statistically significant relation between strabismus and all of the following variables: gestational age, ${ }^{1}$ acute $\mathrm{ROP},{ }^{1516} \mathrm{CP},{ }^{17}$ and abnormal ultrasonic brain scans in early life. ${ }^{17}$ However, all these factors are interrelated ${ }^{16}$ and earlier studies have not been able to identify independent factors associated with strabismus ${ }^{1}$; hence the mechanism of the association between strabismus and prematurity has not been elucidated.

This cohort study confirms the high prevalence of strabismus in premature neonates noted by previous authors ${ }^{1-4} 78$ and documents the prevalence according to gestational age in a geographically defined sample of children with a high follow up rate. Further, the eight children not seen at 2 years by the survey ophthalmologist (mean gestational age at birth of 29.75 weeks, range 26-31) were all seen by an experienced paediatrician for detailed developmental assessment. All were judged to be free of any visual impairment except one child born at 27 weeks' gestation who had an alternating convergent squint.

This study shows a number of factors to be independently related to strabismus-namely, cicatricial ROP, refractive error, family history of strabismus, and measures of coordination (hand-eye coordination and locomotor skills). These associations are not necessarily causative but do seem more understandable than that of regressed acute ROP. ${ }^{18}$ The data concerning the stage of acute ROP were collected retrospectively from examination by a number of ophthalmologists. The incidence of mild acute ROP (stages 1 and 2) was less than would be expected from the natural history study by Fielder et al, ${ }^{19}$ suggesting that some of the milder cases were missed. This may have contributed to the absence of a relation 
between strabismus and the worst stage of acute ROP reached, once cicatricial ROP was included as a predictor of strabismus. However, it does not seem likely that these milder cases would have a substantial effect on the result $(\mathrm{p}=0.85)$, especially if a dose response was anticipated.

Cicatricial ROP, refractive error, family history of strabismus, and measures of coordination are more closely related to the risk of strabismus than gestational age itself (which is not a significant independent risk factor in logistic regression) so they may suggest the possible mechanism by which prematurity predisposes to strabismus. It is useful to consider these associations individually.

CICATRICIAL ROP

One would expect cicatricial ROP to predispose to strabismus as it is usually asymmetrical, with one eye suffering a more severe effect on vision or refractive error or both. Therefore one may have expected the relative risk of strabismus to be higher than the value of 4.94 found in this study. This value may reflect the close association between cicatricial ROP and generalised developmental delay ${ }^{20}$ so that identifying children with cicatricial ROP does not add substantially in predicting strabismus as many of these children are already predicted due to their developmental delay.

\section{REFRACTIVE ERROR}

Large refractive errors have long been recognised as predisposing to strabismus. ${ }^{21}$ Hypermetropia of $4 \mathrm{D}$ or more (spherical equivalent), anisometropia of $>1 \mathrm{D}$, or astigmatism of more than $1.25 \mathrm{D}$ were chosen for the initial analysis because this degree of refractive error has been considered to lead to amblyopia or strabismus or both in some children. ${ }^{21}$ Hypermetropia of $2 \mathrm{D}$ or more rather than $4 \mathrm{D}$ was also tested as glasses to correct $2-3.75 \mathrm{D}$ of hypermetropia may have a significant effect in children who already have strabismus. Hypermetropia of $2 \mathrm{D}$ or more was not a significant risk factor for strabismus, consistent with clinical practice of not prescribing glasses for those with asymptomatic hypermetropia of 2-3.75 D to prevent the development of strabismus.

\section{FAMILY HISTORY OF STRABISMUS}

This is also well recognised in the general population although the mechanism of familial predisposition may be complex..$^{22}$

\section{HAND-EYE COORDINATION AND LOCOMOTOR}

SKILLS

Previous authors have noted a relation between strabismus and other variables (such as regressed acute ROP) which have not necessarily been directly related. ${ }^{18}$ Similarly the association between strabismus and locomotor skills and hand-eye coordination which we have shown may not be cause or effect. The association may merely reflect relations with other variables (as yet unidentified) which are causally related. It is possible that the strabismus and the poor coordination (as measured by the GMDS score) have a common cause or that the strabismus is the cause of the poor GMDS score. Visually guided reaching is more efficient under binocular conditions than monocular conditions. ${ }^{23}$ The lack of stereopsis in strabismus may therefore adversely affect the child's ability to perform some of the GMDS measures of hand-eye coordination (such as building a tower of bricks), although other achievements may be less dependent on stereopsis (such as drawing a perpendicular line in imitation). In support of this argument, Rogers et $a l^{24}$ found improvement in visual reaching within a week of operative correction of infantile esotropia suggesting that strabismus may indeed impair the child's ability to perform some of the GMDS tests. These effects are however quite small and unlikely to account alone for the association between strabismus and coordination skills. Furthermore, those children with very low scores on the locomotor and hand-eye coordination scales were predominately those children with CP and it would seem unlikely that strabismus is the primary cause of deficiencies in these skills in CP. It seems more likely that neurological damage to the motor cortex and pathways which causes CP may contribute to a motor predisposition to strabismus. This may represent a direct effect via damage to the motor cortex/pathways or represent an effect of ischaemia or haemorrhage in other parts of the brain associated with the motor cortex/ pathways damage.

It has not yet been possible to identify an anatomical site of damage causing infantile or childhood concomitant strabismus (reviewed by Hoyt and Good $^{25}$ ). Although children with periventricular leucomalacia have a higher incidence of strabismus than normal children, Scher et $a l^{26}$ found strabismus in only $40 \%$. In this study cranial ultrasound abnormalities were not significant predictors of strabismus in logistic regression using neurological outcome which was a better predictor. This may reflect the classification of abnormalities and the absence of ultrasound data on some children but may also reflect the limitations of ultrasound to detect damage which functionally manifests itself subsequently. Thus, neonatal cranial ultrasound is not able to predict exactly which children will have long term damage to the motor system ${ }^{27}$ or the visual system ${ }^{28}$; some children have impairment despite normal scans $^{27}$ and some function normally despite abnormal scans ${ }^{27} 28$ suggesting compensation by the developing brain. ${ }^{28}$

It is interesting that the association between strabismus and general developmental quotient is not entirely due to the very high incidence of strabismus in those with developmental delay. The increased risk in those with a general developmental quotient below the mean but within the normal range (78-100) may be part of the spectrum extending to those with developmental delay or may reflect the effect of strabismus on the child's ability to perform the Griffiths tests. The absence of a significantly increased risk of strabismus for those with a score below the mean but still within the normal range, when hand-eye 
coordination and locomotor skills were used in the model rather than the general developmental quotient, suggests that if a true association is present it is only weak.

In summary, logistic regression analysis shows that in a population of children born prematurely the increasing prevalence of strabismus with decreasing gestational age is independently associated with cicatricial ROP, refractive error, family history of strabismus, and impaired locomotor and hand-eye coordination. The possibility of a direct causal link with each of these factors has been discussed. As these factors are better predictors of risk of strabismus than gestational age (which is not a significant independent risk factor) they may suggest possible mechanisms by which prematurity predisposes to strabismus.

We are grateful to the neonatal nurses who played a key part in recruiting these children into this prospective region wide follow up study, to the parents and children for their cooperation, and to Sister Susan Fritz for the central role she played in maintaining contact with the families after discharge. We appreciate the work of the neonatologists of the Northern Neonatal Forum, particularly Drs Edmund Hey and Unni Wariyar.

1 Laws D, Shaw DE, Robinson J, et al. Retinopathy of prematurity: a prospective study. Review at six months. Eye 1992;6:477-83.

2 Cats BP, Tan KEWP. Prematures with and without regressed retinopathy of prematurity: comparison of long-term (6-10 years) ophthalmological morbidity. $\mathcal{F}$ Pediatr Ophthalmol Strabismus 1989;26:271-5.

3 Gallo JE, Lennerstrand G. A population-based study of ocular abnormalities in premature children aged 5 to 10 years. Am f Ophthalmol 1991;111:539-47.

4 Keith CG, Kitchen WH. Ocular morbidity in infants of very low birth weight. Br f Ophthalmol 1983;67:302-5.

5 Page JM, Schneeweiss S, Whyte HEA, et al. Ocular sequelae in premature infants. Pediatrics 1993;92:787-90.

6 Hungerford J, Stewart A, Hope P. Ocular sequelae of preterm birth and their relation to ultrasound evidence of cerebral damage. Br F Ophthalmol 1986;70:463-8.

7 Gibson NA, Fielder AR, Trounce JQ, et al. Ophthalmic findings in infants of very low birthweight. Develop Med Child Neurol 1990;32:7-13.

8 Dowdeswell HJ, Slater AM, Broomhall J, et al. Visual deficits in children born at less than 32 weeks' gestation with and without major ocular pathology and cerebral damage. $\mathrm{Br} F$ Ophthalmol 1995;79:447-52.

9 Robinson R, O'Keefe M. Follow up study on premature infants with and without retinopathy of prematurity. $\mathrm{Br} \mathcal{F}$ Ophthalmol 1993;77:91-4.
10 Schaffer DB, Palmer EA, Plotsky DF, et al. Prognostic factors in the natural course of retinopathy of prematurity. Ophthalmology 1993;100:230-7.

11 Northern Neonatal Nursing Initiative Trial Group. Randomised trial of prophylactic early fresh-frozen plasma or gelatin or glucose in preterm babies: outcome at 2 years. Lancet 1996;348:229-32.

12 Griffiths R. The abilities of babies. London: University of London Press, 1956

13 International Committee. An international classification of retinopathy of prematurity. Br f Ophthalmol 1984;68:6907.

14 Cryotherapy for Retinopathy of Prematurity Cooperative Group. Multicenter trial of cryotherapy for retinopathy of prematurity. Snellen visual acuity and structural outcome at $51 / 2$ years after randomization. Arch Ophthalmol 1996;114:417-24.

15 Northern Neonatal Nursing Initiative Trial Group. A randomised trial comparing the effect of prophylactic intravenous fresh frozen plasma, gelatin or glucose on early mortality and morbidity in preterm babies. Eur $\mathcal{F}$ Pediatr 1996;155:580-8.

16 Cryotherapy for retinopathy of prematurity cooperative group. The natural ocular outcome of premature birth and retinopathy. Status at 1 year. Arch Ophthalmol 1994;112: 903-12.

17 Black P. Visual disorders associated with cerebral palsy. $\mathrm{Br} F$ Ophthalmol 1982;66:46-52.

8 Kushner BJ. Strabismus and amblyopia associated with regressed retinopathy of prematurity. Arch Ophthalmol 1982;100:256-61.

19 Fielder AR, Shaw DE, Robinson J, et al. Natural history of retinopathy of prematurity: a prospective study. Eye 1992;6:233-42.

20 Pennefather PM, Tin W, Strong NP, et al. The association between severe retinopathy of prematurity and cerebral palsy-more than just an effect of gestational age. Invest Ophthalmol Vis Sci 1996;S1111 (abstract)

21 Moore A. Refraction of infants and young children. In: Taylor D, editor. Pediatric ophthalmology. Oxford: Blackwell Scientific Publications, 1990:65-70.

22 Graham PA. Epidemiology of strabismus. Br $\mathcal{F}$ Ophthalmol 1974;58:224-31.

23 Servos P, Goodale MA. Binocular vision and the on-line control of human prehension. Exp Brain Res 1994;98:11927.

24 Rogers GL, Chazan S, Fellows R, et al. Strabismus surgery and its effect upon infant development in congenital esotropia. Ophthalmology 1982;89:479-83.

25 Hoyt CS, Good WV. Infantile strabismus: what is it? where is it? Br F Ophthalmol 1994;78:325-6.

26 Scher MS, Dobson V, Carpenter NA, et al. Visual and neurological outcome of infants with periventricular leukomalacia. Dev Med Child Neurol 1989;31:353-65.

27 Roth SC, Baudin J, McCormick DC, et al. Relation between ultrasound appearance of the brain of very preterm infants and neurodevelopmental impairment at eight years. Dev Med Child Neurol 1993;35:755-68.

28 Mercuri E, Atkinson J, Braddick O, et al. Visual function and perinatal focal cerebral infarction. Arch Dis Child 1996;75: F76-81. 